\title{
Current status of some tropical plants with anti-diabetic potential - a Review
}

\author{
S. O. Majekodunmi* ${ }^{1}$ and C. I. Igwilo ${ }^{2}$ \\ ${ }^{I}$ Department of Pharmaceutics and Pharmaceutical Technology, Faculty of Pharmacy, University of Uyo, Uyo, \\ Nigeria, \\ ${ }^{2}$ Department of Pharmaceutics and Pharmaceutical Technology, Faculty of Pharmacy, University of Lagos, \\ Lagos, Nigeria.
}

\begin{abstract}
Summary: Diabetes mellitus and its complications continue to be one of the highest causes of morbidity and mortality in recent times. Although many drugs are commercially available for use in the management of diabetes, their side effects and high costs underscore the need for herbal alternative drugs. This review presents the profiles of plants with hypoglycaemic properties reported in the literature. Profile includes scientific names, common names, regions they were found, traditional uses, degree of hypoglycaemic activity, methodology used and the active agents found in these plants. The families include the most studied such as Cucurbitaceae, Papillionaceae.The most studied species include Momordica charantia, Trigonella foenum graecum, Allium sativum, Allium cepa. Many studies have confirmed the benefits of medicinal plants with hypoglycaemic activity in the management of diabetes mellitus and its complications. Moreover many of the bioactive compounds isolated from these plants have been found to be more effective than oral hypoglycaemic drugs used in medical practice.
\end{abstract}

Keywords: alloxan-induced, antidiabetic, diabetes mellitus, hypoglycaemic.

\section{Introduction}

Diabetic mellitus is a disorder in which the blood sugar (glucose) levels are abnormally high (hyperglycemia) because either the body does not produce enough insulin or the insulin so produced cannot be used by the body [1].

Insulin, a hormone produced and released from the pancrease by the beta cells of the islets of Langerhans controls the amount of sugar in the blood [2]. When a person eats or drinks, food is broken into smaller molecules, including sugar that the body needs to function. Sugar is absorbed into the bloodstream and stimulates the pancrease to produce insulin. Insulin allows sugar to move from the blood into the cells. Once inside the cells sugar is converted to energy, which is either used immediately or stored until it is needed. The levels of sugar in the blood vary normally throughout the day. They rise after a meal and return to normal within about 2 hours after eating. Once the levels of sugar in the blood returns to normal, insulin production decreases. The variation in blood sugar levels is usually within a narrow range, about 70 to 110 milligrams per deciliter $(\mathrm{mg} / \mathrm{dL})$ of blood. If a person has eaten a large amount of carbohydrates, the levels may increase. People older than 65 years tend to have slightly higher levels, especially after eating. If the body does not produce enough insulin to move the sugar into the cells, the resulting high levels of sugar in the blood and the inadequate amount of sugar in the cells together produce the symptoms and complications of diabetes [3]. The full name diabetes mellitus is often used rather than diabetes alone, to distinguish this disorder from diabetes insipidus, a relatively rare disease that does not affect blood sugar levels [4].

\subsection{Types of diabetes mellitus}

There are two major types of diabetes mellitus. The first is Type 1 or Insulin-dependent diabetes mellitus (IDDM) or juvenile-onset diabetes mellitus) and second, Type 2 or Non-insulin-dependent diabetes mellitus (NIDDM) or type 2 adult onset. However, as treatment recommendations evolve, correct classification of the type of diabetes mellitus complicates epidemiological evaluation and clinical management [1]. The new classification system identifies four types of diabetes mellitus: type 1; type 2 as previously mentioned; other specific types and gestational diabetes. Each of the types of diabetes mellitus identified extends across a clinical requirement [5].

\subsubsection{Type 1 diabetes mellitus}

Type 1 diabetes mellitus is characterized by beta cell destruction caused by an autoimmune process, usually leading to absolute insulin deficiency [2]. The onset is usually acute, developing over a period of a few days to weeks. Over $95 \%$ of persons with type 1 diabetes mellitus develop the disease before the age of 25 , with an equal incidence in both sexes and increased prevalence in the white population [6]. Most of these patients 
have the "immune-mediated form" of type 1 diabetes mellitus with islet cell antibodies and often have other autoimmune disorders such as Hachimoto's thyroiditis, Addison's disease and pernicious anemia [6]. A few patients, usually those of African or Asian origin, have no antibodies but have a similar clinical presentation; consequently, they are included in this classification and their disease is called the "idiopathic form" of type 1 diabetes mellitus [7].

\subsubsection{Type 2 diabetes mellitus}

Type 2 diabetes mellitus is characterized by insulin resistance in peripheral tissue and an insulin secretory defect of the beta cell [7]. This is the most common form of diabetes mellitus and is highly associated with a family history of diabetes, old age, obesity and lack of exercise. It is more common in women, especially women with a history of gestational diabetes, and in blacks, Hispanics and native Americans. Insulin resistance and hyperinsulinemia eventually lead to impaired glucose tolerance. Defective beta cells become exhausted, further fueling the cycle of glucose intolerance and hyperglycemia. The etiology of type 2 diabetes mellitus is multifactorial and probably genetically based, but it also has strong behavioral components [8].

\subsection{3 "Other specific types" and gestational diabetes}

Types of diabetes mellitus of various known etiologies are grouped together to form the classification called "other specific types". This group includes persons with genetic defects of beta-cell function (this type of diabetes mellitus was formerly called MODY or maturity-onset diabetes in youth) or with defects of insulin action; persons with diseases of the exocrine pancrease such as pancreatitis or cystis fibrosis; persons with dysfunction associated with other endocrinopathies (e.g. acromegaly); and persons with pancreatic dysfunction caused by drugs, chemicals or infections [2]

Gestational diabetes mellitus is an operational classification (rather than a pathophysiologic condition) identifying women who develop diabetes mellitus during gestation.

\subsection{Complications of diabetes mellitus}

People with diabetes mellitus may experience many serious, long-term complications. Some of these complications begin within months of the onset of diabetes, although most tend to develop years later. Most of the complications are progressive [9].

\subsubsection{Renal complications (nephropathy)}

Nephropathy which develops in only 35 to 45 percent of patients with IDDM and less than 20 percent of those with NIDDM [10],[11],[12]is a complication associated with the greatest mortality. Diabetic nephropathy in IDDM begins with the development of micro albuminuria (30 to $300 \mathrm{mg}$ of albumin per 24 hours), which may occur as early as five years after the onset of diabetes [13],[14],[15],[16],[17]. This stage of incipient nephropathy may be more likely in patients with glomerular hyperfiltration (i.e., a glomerular filtration rate $>150 \mathrm{ml}$ per minute) [17]. After another 5 to 10 years of diabetes, overt proteinuria (> $500 \mathrm{mg}$ of protein per liter, equivalent to $>300 \mathrm{mg}$ of albumin per 24 hours) develops in patients destined to have end-stage renal disease. Hypertension invariably develops during this period. In the next 5 to 10 years, the nephrotic syndrome develops and the glomerular filtration rate falls, resulting in end-stage renal disease. The mean durations of IDDM before the development of overt proteinuria and end-stage renal disease are 17 and 23 years, respectively [18]. Although a small fraction of patients with IDDM who have nephropathy may die of uremia, the majority die of concurrent cardiovascular disease, the risk of which is 30 to 40 times that in patients with IDDM who do not have nephropathy [19].

Microalbuminuria appears to precede nephropathy in patients with NIDDM, as it does in those with IDDM [17]. End-stage renal disease is characterized by small, atrophic kidneys with diffuse glomerulosclerosis [20].

\subsubsection{Ocular complications (retinopathy)}

The eyes can be affected in several ways by diabetes mellitus. Diabetes retinopathy is one of the leading causes for irreversible blindness in the United States. This retinopathy can occur with either Type 1 or Type 2 diabetes mellitus, and the development depends on the duration of the disease [21], [22]. Most persons with type 1 diabetes and many of those with type 2 diabetes develop some background (non proliferative) retinopathy. Proliferative retinopathy is more ominous and is more likely to occur when diabetes mellitus is poorly controlled.

\subsubsection{Neuropathy}

A peripheral, symmetric sensorimotor neuropathy is the most common form of diabetic neuropathy, whose other forms include cranial and peripheral motor neuropathies and autonomic neuropathy. Although 
neuropathy is also more common with a longer duration of diabetes, Said et al., (1992) [23] described a relatively severe, early-onset polyneuropathy.Electrophysiologic studies demonstrate subclinical abnormalities, including slowed motor- and sensory-nerve conduction in most patients, after 5 to 10 years of diabetes.

Because loss of sensation in the feet and altered foot architecture make foot care problematic, the principal risk posed by peripheral neuropathy is of foot trauma and diabetic ulcers. A minority of patients have painful peripheral neuropathy with lancinating or burning dysesthesia, severe enough in some to be associated with depression and anorexia [24].Autonomic neuropathy can affect gastric or intestinal motility, erectile function, bladder function, cardiac function, and vascular tone. Impotence is the most common clinical manifestation of autonomic neuropathy, affecting more than 50 percent of men with diabetes. Cardiac autonomic neuropathy may result in resting tachycardia and postural hypotension.

\subsubsection{Cardiovascular disease}

Cardiovascular disease is generally similar in patients with IDDM or NIDDM and patients without diabetes. The chief difference in cardiovascular disease in diabetic as compared with nondiabetic patients (especially women) is its increased frequency [25]. In addition, coronary disease develops at a younger age in diabetic patients than nondiabetic patients, especially if renal disease supervenes. Although asymptomatic coronary artery disease and myocardial infarction are probably not much more common in diabetic patients than in nondiabetic patients [26],[27] atypical anginal symptoms, including symptoms of congestive heart failure, are more common clinical presentation of coronary artery disease in those with diabetes ([26]. Mortality from first or subsequent myocardial infarctions is higher in diabetic than nondiabetic patients [26],[28].

The increased prevalence of coronary artery disease in diabetes is preceded by a constellation of risk factors [29], [30]. Patients with NIDDM (and patients with impaired glucose tolerance) are commonly obese and have hypertension and dyslipidemia (increased serum triglyceride and decreased high-density lipoprotein cholesterol concentrations). Independently of these variables, diabetes remains a major risk factor for coronary artery disease [31]; its effect may be mediated in part through the occurrence of renal disease. The level of chronic glycemia, as determined by measurements of glycosylated hemoglobin, may also be an independent risk factor for coronary artery disease, particularly in women [26].

Other long-term complications, including a predilection for certain infections (e.g., pseudomonas "malignant" external otitis, monilial skin infections, and rhinocerebral mucormycosis) and cognitive impairment, have been identified [32], [33]. Dupuytren's contractures and periarticular thickening of the skin leading to decreased mobility of the fingers are also more common in patients with diabetes.

\subsubsection{Atherosclerosis}

Persons with diabetes mellitus, either type 1 or type 2, have early and accelerated atherosclerosis. The most serious complications of this are atherosclerotic heart disease, cerebrovascular disease, and renal disease. The most common cause of death with diabetes mellitus is myocardial infarction. Peripheral vascular disease is a particular problem with diabetes mellitus and is made worse through the development of diabetic neuropathy leading to propensity for injury.

\subsubsection{Mucormycosis}

This is a feared complication of diabetes mellitus. Diabetic ketoacidosis helps to potentiate the growth of mucor. This site of involvement is typically the nasophryngeal region, but the infection can spread to involve soft tissue and bone of the, orbit, skull, and brain.

\subsection{Anti-diabetic drugs}

\subsubsection{Insulin replacement therapy}

People with type 1 diabetes almost require insulin therapy, and many people with other diabetes require it as well. Insulin is usually injected. It currently can not be taken by mouth as insulin is destroyed in the stomach.

Insulin is injected under the skin into the fat layer, usually in the arm, thigh, or abdominal wall. Small syringes with very thin needles make the injections nearly painless. An air pump device that blows the insulin under the skin can be used for people who cannot tolerate needles. An insulin pen, which, contain a cartridge that holds the insulin, is a convenient way for many people to carry insulin, especially for those who take several injections a day outside the home. Another device is an insulin pump, which pumps insulin continuously from a reservoir through a small needle left in the skin.

Insulin is available in three basic forms, each with a different speed of onset and duration. Rapid-acting insulin such as Insulin Lispro (Humalog) has the fastest onset and shortest duration of action. Rapid-acting insulin is often used by people taking several daily injections and is injected 15 to 20 minutes before meals or just after, activity is between 1-2 $\mathrm{h}$ in the body, and duration of action is $2-4 \mathrm{~h}$. 


\subsubsection{Intermediate-acting insulin}

Such as Insulin zinc suspension, lente, or isophane insulin (ultralente) starts to work in 1 to 3 hours, reaches its maximum activity in 6-10 hours. This type of insulin may be used in the morning for the first part of the day and evening during the night.

\subsubsection{Long acting insulin}

Long acting (such as extended insulin suspension, ultra-lente, or glargine (Lantus) has very little effect for about 6 hours but the duration of action lasts for 36 hours.

Insulin preparations are stable at room temperature for months, allowing them to be carried to work, or taken on a trip. Insulin should not, however, be exposed to extreme temperatures.

The following factors are considered before deciding which insulin preparation is most suitable for the patient:,

- how willing and able the person is to monitor the blood sugar levels and adjust to dosage.

- how varied the person's daily activity is.

- how adept the person is at learning about and understanding the disease.

-how stable the person's blood sugar levels are during the day and from day to day.

\subsubsection{Oral antihyperglycemic drugs}

Oral antihyperglycaemic drugs are used for the treatment of hyperglycaemia and can often lower blood sugar or glucose levels adequately in people with type 2 diabetes or non-insulin-dependent diabetics. Classes of drugs used include:

\subsubsection{Sulfonylureas}

The main action of sulphonylureas is to stimulate insulin secretion from pancreatic beta-cells, but in addition they have two other extrapancreatic actions. In the liver, they decrease hepatic gluconeogenesis and reduce hepatic insulin degradation, and in peripheral tissues such as muscle and fat cells, they enhance the peripheral utilization of glucose by increasing insulin receptor binding sites. Examples are acetohexamide, glyburide, chlorpropamide, glimepriride, glipzide, tolazamide and tolbutamide.

The sulphonylureas are rapidly absorbed from the gastrointestinal tract (GIT) and are metabolised in the liver and excreted in the urine. They are classified into two groups:

(a) First generation- eg tolbutamide, chlorpropamide

(b) Second generation- eg glibenclamide, glipizide, gliclazide.

The second-generation drugs are more expensive and are of higher potency.

Sulphonylureas are transported in the blood, bound to plasma proteins and they become active when released from these protein complexes. Hence, drugs that bind to plasma proteins will displace the sulphonylureas from the protein-binding sites causing increased bioavailability and hypoglycaemic effects. Such drugs include salicylates (high dose), barbiturates, monoamine oxidase inhibitors (MAOls), phenylbutazone, sulphonamides, co-trimoxazole, phenytoin, clofibrate and warfarin. The non-selective beta adrenoceptor antagonists may mask the symptoms and signs of hypoglycaemia and in addition delay the recovery from hypoglycaemia by inhibiting gluconeogenesis and glycogenolysis. Drugs that cause hyperglycaemia like thiazide diuretics, frusemide, corticosteroids, contraceptive pills and diazoxide may require an increase to be made in the dosage of sulphonylurea.

Elderly patients are particularly prone to the dangers of hypoglycaemia when long-acting sulphonylurea are used. Chlorpropamide and glibenclamide should be avoided in these patients and replaced by others, such as gliclazide or tolbutamide. The sulphonylureas tend to encourage weight gain. Metformin should be considered for patients who are obese. They should not be used during lactation while the short-acting tolbutamide may be used in renal impairment but careful monitoring of blood-glucose concentration is essential. Care is required in choosing smallest possible dose that produces adequate control of blood glucose. They should be avoided in porphyria and ketoacidosis. Side effects are generally mild and infrequent and include gastro-intestinal disturbances and headache.

Side-effects of sulphonylureas are generally mild and infrequent and include gastro-intestinal disturbances such as nausea, vomiting, diarrhoea and constipation.

Chlorpropamide has appreciably more side-effects, mainly because of its very prolonged duration of action and the consequent hazard of hypoglyceamia and it should no longer be used. Chlorpropamide may also enhance antidiuretic hormone secretion and very rarely cause hyponatraemia (hyponatreamia is also reported with glimepiride and glipizide).

Sulphonylureas can occasionally cause a disturbance in liver function, which may rarely lead to cholestatic jaundice, hepatitis, and hepatic failure. Hypersensitivity reactions can occur, usually in the first 6-8 weeks of therapy. They consist mainly of allergic skin reactions which progress rarely to erythema multiforme and exfoliative dermatitis, fever, and jaundice. Photosensitivity has rarely been reported with chlorpropamide 
and glipizide. Blood disorders are also rare but may include leucopenia, thrombocytopenia, agranulocytosis, pancytopenia, haemolytic anaemia, and aplastic anaemia.

\subsubsection{Biguanides}

Metformin is a biguanide which acts by (a) direct stimulation of glycolysis in peripheral tissues, with increased glucose removal from blood; (b) reduced hepatic gluconeogenesis; (c) slowing of glucose absorption from the GIT; (d) reduction of plasma glucagon levels; and (e) increased insulin binding to insulin receptors. Their blood glucose-lowering action does not depend on the presence of functioning pancreatic B cells.

Metformin is the drug of choice in grossly obese patients in whomstrict dieting hasfailed to control diabetes. It is also used when diabetes is inadequately controlled withsulphonylureas. Hypoglycaemia is not a problem with metformin. Other advantages are the lower incidence of weight gain and lower plasma insulin concentration. It does not exert a hypoglycaemic action in non-diabetic subjects unless in overdose.

Metformin is rapidly absorbed from the gut but it isnot protein-bound in the plasma nor metabolised to any degree by theliver. It is excreted unchanged by the kidney within 24 hours. Its mean plasma half-life is about 2-3 hours. It often induces anorexia, and diarrhoea. It is suited for obese diabetic.

\subsubsection{Meglitinides}

Meglitinidesstimulate the pancrease to produce more insulin and have a rapid onset of action and short duration of activity, and should be administered shortly before each main meal. Examples are nateglinide and repaglinide. Repaglinide may be given as monotherapy to patients who are not overweight or those in whom metformin is contra-indicated or not tolerated, or otherwise it may be given in combination with metformin. Nateglinide is licensed only for use with metformin.

\subsubsection{Thiazolidinediones}

Thiazolidinedionesreduce peripheral insulin resistance, leading to a reduction of blood-glucose concentration. Examples are pioglitazone and rosiglitazone. Either drug can be used alone or in combination with metformin or with the sulphonylurea (if metformin is inappropriate). The combination of a thiazolidinedione with metformin is preferred to a thiazolidinedione - sulphonylurea combination particularly for obese patients. Inadequate response to a combination of metformin and sulphonylurea may indicate failing insulin release. The introduction of pioglitazone or rosiglitazone has a limited role in these circumstances and the initiation of insulin is often more appropriate. Blood-glucose control may deteriorate temporarily when a thiazolidinedione is substituted for an oral antidiabetic drug that is being used in combination with another. Long-term benefits of the thiazolidinediones have not yet been demonstrated. The National Institute for Health and Clinical Excellence (NICE) in May, 2009 annual review published online has recommended that, when glycaemic control is inadequate with existing treatment, a thiazolidinedione can be added to:

- a sulphonylurea, if metformin is contra-indicated or not tolerated;

- metformin, if risks of hypoglycaemia with sulphonylurea are unacceptable or a sulphonylurea is contraindicated or not tolerated;

- combination of metformin and a sulphonylurea, if insulin is unacceptable because of lifestyle or other personal issues, or the patient is obese.

The Scottish Medicines Consortium accepted use of thiazolidinedione (rosiglitazone (June 2006), pioglipazone (February 2007) with metformin and a sulphonylurea, for patients (especially if overweight) whose glycaemic control is inadequate despite the use of 2 oral hypoglycaemic drugs and who are unable or unwilling to take insulin. In this instance, treatment should be initiated and monitored by an experienced diabetes physician.

\subsubsection{Glucosidase inhibitors}

Another class of drug is glucosidase inhibitors such as acarbose and miglitol, which work by delaying the digestion and absorption of starch and glucose in the intestines. The drugs are sometimes taken only in the morning, although some people need two or three doses. It has a small but significant effect in lowering blood glucose. Postprandial hyperglycaemia in type 1 diabetes can be reduced by acarbose. Flatulence deters some from using acarbose although this side-effect tends to decrease with time.

\subsubsection{Dipeptidylpeptidase inhibitors}

Dipeptidylpeptidase inhibitors increase insulin secretion and lower glucagon secretion. Examples aresitagliptinand vildagliptin. Both drugs are licensed for use in type 2 diabetes in combination with metformin or a sulphonylurea (if metformin is inappropriate). Sitagliptin is also licensed for use in combination with both metformin and a sulphonylurea when dual therapy with these drugs fails to achieve adequate glycaemic control. 
The National Institute for Health and Clinical Excellence (NICE, May 2009) has recommended that, when glycaemic control is inadequate with existing treatment:

- sitagliptin or vildagliptin (instead of a sulphonylurea) can be added to metformin, if there is a significant risk of hypoglycaemia or if a sulphonylurea is contra-indicated or not tolerated;

- sitagliptin or vildagliptin can be added to a sulphonylurea, if metformin is contra-indicated or not tolerated;

- sitagliptin can be added to both metformin and a sulphonylurea, if insulin is unacceptable because of lifestyle or other personal issues.

The National Institute for Health and Clinical Excellence (NICE, May 2009) also recommended that when glycaemic control is inadequate with metformin and sulphonylurea treatment, the addition of exenatide might be considered if the patient has:

- a body mass index of $35 \mathrm{~kg} / \mathrm{m}^{2}$ or over and is of European descent (with appropriate adjustment for other ethnic groups) and weight-related psychological or medical problems or

- a body mass index less than $35 \mathrm{~kg} / \mathrm{m}^{2}$, and insulin would be unacceptable for occupational reasons or weight loss would benefit other significant obesity-related morbidities.

\subsection{Use of medicinal plants for the treatment of diabetes mellitus}

The importance of anti-diabetic plants in the development of economic and effective treatment for diabetes, currently estimated to affect over 30 million people worldwide, has been recognized by the World Health Organization [34].

Anti-diabetic plants have often been used by practitioners of herbal medicine in treating individuals with non-insulin-dependent (type 2) diabetes. However, the use of such herbs by type 1 (insulin- dependent) diabetics can be hazardous and requires that such patients carefully monitor their blood sugar to prevent hypoglycemic and hyperglycemic episodes [35].

Some of the plants that have shown varying degree of hypoglycemic activity include:

\subsubsection{Momordica charantia L (Karela) or (Balsam pear),}

Momordica charantiaL., Family Cucurbitaceaeknown as Bitter melon is used primarily as an alternative therapy for diabetes for thousands of years. Bitter melon has a long history of use as a hypoglycemic agent in Asia, Africa, and Latin America, where the plant extract has been referred to as vegetable insulin. Data from in vitro, animal and designed human studies do suggest that bitter melon and some of its crude extracts have a moderate hypoglycemic effect [36].In healthy mice, an aqueous extract obtained from Momordica charantia L. attenuated the glycaemic response to both oral and intraperitoneal glucose, without altering the insulin response. This aqueous extract and the residue after alkaline chloroform extraction reduced hyperglycaemia in diabetic mice after 1 hour. It was concluded that the hypoglycaemia activity of orally administered M. charantia extracts was independent of intestinal glucose absorption and involved an extrapancreatic effect [37]. A $50 \%$ methanolic extract $(30 \mathrm{mg} / \mathrm{kg}$ ) caused a decrease in blood glucose level (BGL) 3 hours after oral administration to streptozotocin-induced diabetic rats. Other fractions, such as the n-butanol soluble fraction from M. charantia extract, were most effective in lowering BGL. The n-butanol fraction of M. charantia inhibited the increase of BGL prominently after intraperitoneal glucose load. Like the action of sulfonylureas [38], the M. charantia extract seems to act like insulin or via insulin secretion from the pancreas. The aqueous fruit extract decreased the fasting glucose level in normoglycaemic and cyproheptadine-induced hyperglycaemic mice. The alcoholic extract of the pulp $(500 \mathrm{mg} / \mathrm{kg})$, administered to healthy glucose-primed rats depressed plasma glucose levels at 1 hour. Tolbutamide $(100 \mathrm{mg} / \mathrm{kg})$, under similar conditions, produced the same effect. This reduction in plasma glucose levels was not accompanied by increased insulin secretion. In streptozotocin-induced diabetic rats, it improved the oral glucose tolerance causing significant reduction in plasma glucose. These data suggest that the mechanism of action of this plant could partly be attributed to increased glucose utilization by the liver rather than an insulin secretion effect [39].

\subsubsection{Caesalpinia bonducella}

Caesalpinia bonducella F., (Leguminosae) commonly known as Nata Karanja in Spanish, is a prickly shrub found throughout the hotter parts of India, Myanmar, Sri Lanka, Bangladesh. It is reported to have antipyretic, antidiuretic, anthelmintic and antibacterial [40], antianaphylactic and antidiarrhoeal [41] antiviral [42], antiasthmatic [43], antiemetic and antiestrogenic properties [44].

Traditionally, the tribes of Andaman and Nicober Island in the Bay of Bengal and a union Territory of India used the aqueous decoction of the seeds of this plant, simply by rubbing on a stone, to eliminate the symptoms of diabetes mellitus. This ethnic lead necessitated the exploration of Caesalpinia bonducella seeds for their antidiabetic activity. Blood sugar lowering activity of Caesalpinia bonducella has been primarily evaluated with significant results in rabbit[45]. Hypoglycemic activity of different extracts of Caesalpinia bonducella seed shell has been reported in physiological hyperglycemic and type 1 and type 2 diabetic model rats [46], [47]. 
In healthy rats, both the aqueous and $50 \%$ ethanolic extracts of Caesalpinia bonducella Fleming seeds exhibited hypoglycaemic activity as early as $4 \mathrm{~h}$ after administration at a dose of $100 \mathrm{mg} / \mathrm{kg}$. The hypoglycaemia produced by the aqueous extract was of prolonged duration as compared to the ethanolic extract. In diabetic rats, both extracts produced marked antihyperglycaemic effects from day 5 onwards [48].

\subsubsection{Bauhinia divaricata}

Bauhinia divaricatais an ornamental nice looking small tree that bear small white flower that turns pink with time. In laboratory experiment Bauhinia divericata revealed hypoglycemic (antidiabetic) effect [49], [50]. A study was performed using healthy rabbits with intragastric administration of water, tolbutamide or decoction of the tested plant before the induction of hyperglycaemia by subcutaneous injection of $50 \%$ dextrose solution $(4 \mathrm{ml} / \mathrm{kg}$ ) at 0 and $60 \mathrm{~min}$. Tolbutamide and Bauhinia divaricata significantly decreased hyperglycaemia compared with control. [49]. The hypoglycaemic activity of a $20 \%$ dried leaf infusion of Bauhinia candicans Benth. did not modify the glycaemia in healthy rats, but in alloxan-induced diabetic rats it produced a decrease in glycaemia (39\%) [50].

\subsubsection{Trigonella foenum graecum L. (fenugreek)}

Trigonella foenum graecum, commonly called fenugreek, is a leguminous plant native to many Asian, Middle Eastern, and European countries [51] where its seeds and leaves are edible and used as condiments and in Ayurvedic medicine in the Indian subcontinent to treat diabetes, high cholesterol, wounds, inflammation, and gastrointestinal ailments [52]. Fenugreek seeds have been successfully tested in laboratory animals and in humans with type 1 and type 2 diabetes as a hypoglycemic agent [36],[53],[54],[55],[56],[57],[58],[59], [60], [61], [62], [63], [64]. The potential of fenugreek seeds to modulate several enzymes, including those associated with glucose and lipid metabolism, has been documented [65]. Among bioactive compounds isolated from fenugreek seeds are protodioscin, trigoneoside, diosgenin, yamogenin, and others [66], [67]. Fenugreek is among twelve herbs mostly used to treat diabetes in Saudi Arabia [68]. In insulin-dependent diabetic patients, the fenugreek diet significantly reduced fasting blood glucose and improved the glucose tolerance test. There was a 54\% reduction in the 24 hours urinary glucose excretion. The results showed the usefulness of fenugreek seeds in the management of diabetes [69]. Oral administration of T. foenum graecum to healthy and alloxan induced diabetic rats $(2$ and $8 \mathrm{~g} / \mathrm{kg}$ ) produced a significant fall in blood glucose level (BGL) both in the normal as well as in diabetic rats. The hypoglycaemic effect was dose related [70]. On the other hand, the aqueous extract of fenugreek leaf when given to both healthy and alloxan-diabetic rats, produced a significant reduction in BGL. However, an ethanolic extract of fenugreek leaf produced no reduction in BGL in healthy rats but (intraperitoneal) i.p. administration of $0.8 \mathrm{~g} / \mathrm{kg}$ of the ethanolic leaf extract to diabetic rats produced a significant reduction of BGL. The Soluble Dietary Fibers (SDF) fraction of fenugreek seeds showed no effect on fasting blood glucose levels of non-diabetic or NIDDM (type II) rats. However, when fed simultaneously with glucose, it showed a hypoglycaemic effect in type II diabetic rats. The major constituent of the SDF is galactomannan [71]. When steroid and saponins extracted from the seed of fenugreek were administered chronically mixed with food (12.5 mg/day per $300 \mathrm{~g}$ body weight) to healthy and streptozotocin-induced diabetic rats, food intake and the motivation to eat in healthy rats were significantly increased and the food consumption in diabetic rats was also stabilized. In both healthy and diabetic rats, steroid and saponins decreased total plasma cholesterol without any change in triglycerides [72]. Activity was also attributed largely to high fibre content [70]the amino acid 4-hydroxyisoleucine [73] and the major alkaloid trigonelline [55].More recently, it has been shown that the disrupted free radical metabolism in diabetic animals may be normalized by fenugreek seed supplementation in the diet [74]. Moreover, fenugreek significantly decreased the hyperglycaemic peak and the area under the glucose tolerance curve in hyperglycaemic rabbits [75]. Anti-hyperglycemic effect was linked to delayed gastric emptying caused by the high fiber content, inhibiting of carbohydrate digestive enzymes [70] and stimulating of insulin secretion [71].

\subsubsection{Allium sativum (Garlic)Fam. Liliaceae}

Garlic has a very long folk history of use in a wide range of ailments, particularly ailments such as ringworm, candida and vaginitis where its fungicidal, antiseptic, tonic and parasiticidal properties have proved of benefit. The plant produces inhibitory effects on gram-negative germs of the typhoid-paratyphoid-enteritis group. Indeed it possesses outstanding germicidal properties and can keep amoebic dysentery at bay. It is also said to have anticancer activity. It has also been shown that garlic aids detoxification of chronic lead poisoning. Daily use of garlic in the diet has been shown to have a very beneficial effect on the body, especially the blood system and the heart. For example, demographic studies suggest that garlic is responsible for the low incidence of arteriosclerosis in areas of Italy and Spain where consumption of the bulb is heavy.

Oral administration of the ethanol extract, juice and oil of bulb of A. sativum L. remarkably lowered blood sugar in normal and alloxan-induced diabetic rats or rabbits, with an efficacy closely related to tolbutamide 
[76],[77],[78],[79], [80]. S-allyl cysteine sulphoxide (SACS), a sulphur-containing amino acid of Allium sativum L. (Garlic) that is the precursor of allicin and garlic oil, has been found to show significant antidiabetic effects in alloxan diabetic rats. Administration of a dose of $200 \mathrm{mg} / \mathrm{kg}$ significantly decreased the concentration of serum lipids, blood glucose and activities of serum enzymes like alkaline phosphatase, acid phosphatase and lactate dehydrogenase and liver glucose-6-phosphatase. It significantly increased liver and intestinal HMG CoA reductase activity and liver hexokinase activity [81]. Oral administration of SACS to alloxan diabetic rats for a month ameliorated the diabetic conditions of treated rats comparable with rats treated with glibenclamide and insulin [82].The anti-hyperglycemic mechanism of SACS is to stimulate in vitro insulin secretion from cells of pancreatic islet, increase serum insulin level, improve glucose tolerance and increase liver glycogen synthesis [83],[84], [85], [86], [87]. Hence it can be surmised that the beneficial effects of SACS could be due to both its antioxidant and its secretagogue actions. The former effect is predominant and the latter is only secondary [88]. The garlic extract can prevent diabetic cardiovascular complications [77].

\subsubsection{Allium cepa L (Onion)}

Although rarely used specifically as a medicinal herb, the onion has a wide range of beneficial actions on the body and when eaten (especially raw) on a regular basis will promote the general health of the body and offsets tendencies towards angina, arteriosclerosis and heart attack. The bulb of A. cepa L. is anthelmintic, antiinflammatory, antiseptic, antispasmodic, carminative, diuretic, expectorant, febrifuge, hypoglycaemic, hypotensive, lithontripic, stomachic and tonic. It is also useful in preventing oral infection and tooth decay. Baked onions can be used as a poultice to remove pus from sores. Fresh onion juice is a very useful first aid treatment for bee and wasp stings, bites, grazes or fungal skin complaints. When warmed, the juice can be dropped into the ear to treat earache. It also aids the formation of scar tissue on wounds, thus speeding up the healing process, and has been used as a cosmetic to remove freckles. Bulbs of red cultivars are harvested when mature in the summer and used to make a homeopathic remedy. This is used particularly in the treatment of people whose symptoms include running eyes and nose. Oral administration of Allium cepa L. (Onion), Smethyl cysteine sulphoxide (SMCS) daily at a dose of $200 \mathrm{mg} / \mathrm{kg}$ body weight for a period of 45 days to alloxan diabetic rats controlled the blood glucose and lipids in serum and tissues and altered the activities of liver hexokinase, glucose 6- phosphatase and HMG CoA reductase towards normal values. These effects of SMCS were comparable to those of glibenclamide and insulin [89].. Oral administration of onion SMCS to alloxan diabetic rats for a month, ameliorated the diabetic condition similar to rats treated with glibenclamide and insulin. The effect of feeding a $15 \%$ capsaicin diet or $3 \%$ freeze-dried onion powder containing diet produced a significant reduction in the hyperglycaemic status of diabetic animals. This study revealed that onion feeding improves the metabolic status in diabetes probably because of its hypocholesterolemic as well as its hypoglycaemic effect [89].

\subsubsection{Aloe barbadense Mill (Barbados)}

Aloe barbadensis Mill fresh juice obtained from the cut bases of the Aloe leaves is cathartic and cooling. The juice is often used to treat eye diseases, liver and spleen ailments, muscular pain, dermatitis, burns, cutaneous leishmaniasis and other skin problems. To relieve burns, insect and fish bites, skin ailments, arthritis, myopathies, Aloe babadensis Mill is used as external application. The plant is also used for manufacturing beauty products as hair conditioners and skin creams. The rural inhabitants of Gujarat in India use the pulp of the leaf to cure piles, boils, burns and swellings. It is considered effective to reduce excessive body fats.

Acute oral administration of an exudate of Aloe barbadensis Mill. (Barbados) leaves (500 mg/kg) producedno reduction in blood glucose level whereas its bitterprinciple $(5 \mathrm{mg} / \mathrm{kg})$ administered intraperitoneallyproduced a significant hypoglycaemic effect that extendedover a period of 24 hours with maximum hypoglycaemiaobserved after 8 hours. In chronic studies, A. barbadensis and its bitter principle produced a maximum effect after 5 days. It seems that the hypoglycaemic effect of this plant and its bitter principle may be mediated through stimulating synthesis and/or release of insulin from the beta-cells of the islets of Langerhans [90] (Ajabnoor, 1990). Moreover, thisplant slightly decreased the area under glucose tolerance curve compared to control (1.4\%) or tolbutamide (14.3\%)in healthy rabbits [49].

\subsubsection{Azadirachta indica $L$}

All parts of Azadirachta indica have been used medicinally for centuries. It is widely used in toothpastes, soaps and lotion today, as well as being a biological insecticide.

An Azadirachta indica leaf extract was found to have no action on peripheral utilization of glucose or on hepatic glycogen in healthy and streptozotocin-induced diabetic rabbits. The reduction in peripheral utilization of glucose and glycogenolytic effect due to epinephrine was blocked by the A. indica leaf extract, almost completely in diabetic rabbits and to a certain extent in healthy animals [91]. More recently, it has been demonstrated that in an in vitro rat pancreas preparation, A. indica leaf extract significantly blocked the 
inhibitory effect of serotonin on insulin secretion mediated by glucose [92]. Furthermore, A. indica leaf extract was found to have the most potent blood sugar-loweringfollowed by Catharantus roseus, Gymnema sylvestre and Ocimum sanctum [92].

\subsubsection{Eugenia jambolana Lam. $($ Gambol $)=$ Syzigium cumini Skeels $($ Jamum $)$}

Both the fruit pulp and seed extracts of the Jamun berry have a long history of medicinal use and they have been extensively studied for their anti-diabetic properties [93].The hypoglycaemic activity of the extract of jamum pulp from the fruit of Eugenia jambolana Lam. (Gambol), also called Syzigium cumini Skeels (Jamum) was seen after $30 \mathrm{~min}$, while the seeds of the same fruit required $24 \mathrm{~h}$ to produce the same effect. These results were confirmed in streptozotocin-induced diabetic animals. The oral administration of the extract resulted in the enhancement of insulinemia in normoglycaemic and diabetic rats. The incubation of isolated pancreatic islet cells of normal and diabetic animals with this plant extracts resulted in increased insulin secretion. This extract inhibited insulinase activity in the liver and kidney [94]. Oral administration of 2.5 and $5.0 \mathrm{~g} / \mathrm{kg}$ body weight of the aqueous extract of the seeds of S. cumini for six weeks in alloxan-diabetic rats resulted in a significant reduction in blood glucose concentration and an increase in total haemoglobin, but in the case of $7.5 \mathrm{~g} / \mathrm{kg}$ body weight, the effect was not significant. It also resulted in decreased free radical formation in tissues [95].

\subsubsection{Musa sapientum Kuntze (Banana)}

Among the plants most used in the treatment of diabetes mellitus Musa sapientum Kuntze (Banana) significantly decreased the hyperglycaemic peak and the area under the glucose tolerance curve in hyperglycaemic rabbits [96]. Oral administration of $1.5,0.2$ and $0.25 \mathrm{~g} / \mathrm{kg}$ body weight of the chloroform extract of the flowers of M. sapientum during a 30-day period caused a decrease in blood glucose and glycosylated haemoglobin levels and an increase in total haemoglobin. The extract showed antihyperglycaemic action and an antioxidant effect. Banana flower was more effective than glibenclamide [97].

\subsubsection{Mucuna pruriens (Linn)}

Mucuna is an annual climbing and twinning plant that grows $3-18 \mathrm{~m}$ in height. It is indigenous to tropical regions, especially Africa, India, and the West Indies. The plant also produces clusters of pods, which contain seeds known as Mucuna beans. The seed pods are covered with reddish-orange hairs that are readily dislodged and can cause intense irritation to the skin. The species name "pruriens" comes from the Latin which means "itching sensation." These hairs contain mucunian and serotonine causing blisters and dermatitis. The hairs have been used in itching powder and mixed with honey and used as vermifuge.

The administration of the various doses of ethanolic seed extract of Mucuna pruriens led to the dose-dependent reduction in the blood glucose level in both acute and chronic administrations more effective than that observed for glibenclamide as a standard drug.The administration of $5,10,20,30,40,50$ and $100 \mathrm{mg} / \mathrm{kg}$ of the crude ethanolic extract of M. pruriens resulted in $18.6 \%, 24.9 \%, 30.8 \%, 41.4 \%, 49.7 \%, 53.1 \%, 55.4 \%$ reduction, respectively in blood glucose of the diabetic rats after 8 hours of treatment while the administration of glibenclamide (5 mg/kg body weight) resulted in 59.7\% reduction [98].Daily administration of 5, 10, 20,30, 40, 50 , and $100 \mathrm{mg} / \mathrm{kg} /$ body weight of the extract resulted in $55.5 \%, 59.5 \%, 68.4 \%, 74.7 \%, 78.4 \%, 80.9 \%$ and $83.2 \%$ reduction in blood glucose level, respectively after 12 weeks. On the other hand, the standard drug, glibenclamide $(5 \mathrm{mg} / \mathrm{kg})$, resulted in $57.8 \%$ reduction in blood glucose level of the diabetic rats[98].The ethanol extract might be producing its hypoglycaemic effect by an extra-pancreatic action [99] as well as mimicking the function of insulin. The studies showed that the oral administration of ethanol extract of the seeds of M.pruriensdecreased blood glucose level in diabetic rats.

\subsubsection{Catharanthus roseus L. (Apocynaceae)}

Though traditionally used as an anticancer agent the hot water decoction of the leaves and whole plant have antidiabetic activity and been used in subtropical and tropical areas of the world.. The alcoholic extract of the leaves of C. roseus has blood glucose lowering activity.[100][92], [101].The herb has prophylactic activity against the necrotic actions on alloxan monohydrate[102], [103],[104].It has found its use in some clinic in Eastern and South Africa in [lace of insulin [105].In another study, oral administration at 0.5, 0.75 and 1.0 $\mathrm{mL} / \mathrm{kg}$ body weight led to a dose dependent reduction of both normal and diabetic rabbits comparable to that of the standard drug, glibenclamide and the and the mode of action of the active compound(s) is probably mediated through enhance secretion of insulin from the betacells of Langerhans or through extra pancreatic mechanism[106].The extract may be helpful in the prevention of damage caused by oxygen free radicals and increase in glucose utilization [101]. 


\subsubsection{Psidium guajava L. (Myrtaceae)}

Ethanol stem bark extract exhibits statistically significant hypoglycemic activity in alloxan-induced hyperglycemic rats but devoid of hypoglycemic effect in normal and glucose loaded rats [107]. The aqueous extract of P. guajava leaves lowers blood glucose [108],[109], [110],[111].Aqueous extract shows hypolipidaemic activity in addition to its hypoglycemic and antidiabetic activity [112].Flavonoid glycosides such as strictinin, isostrictinin and pedunculagin are the effective constituents [109]. A glycoproteinwith the molecular weight of 50,000-100,000 wasalso identified as active component for anti-diabetes [110].

\subsubsection{Aloe vera L. Burm. (Asphodelaceae)}

Aloe veragrows in arid climates and is widely distributed in Africa, India and other arid areas. Diabetic rats treated with Aloe vera water extract orally at a dose of $150 \mathrm{mg} / \mathrm{kg}$ of body weight led to a significant blood glucose reduction after 30 days of treatment. Statistical analysis of results found that Aloe vera water extract has antidiabetic effect in normal and alloxan induced diabetic rats[113], and glycosylated hemoglobin (HbA1c) with a significant decrease in serum levels of triglycerides, total cholesterol, low density lipoprotein cholesterol and a concomitant increase in high density lipoprotein cholesterol [114].

\section{Conclusion}

All the drugs both herbal and synthetic discussed in this review have exhibited significant clinical \& pharmacological activity. The potency of herbal drugs is significant $\&$ they have negligible side effects than the synthetic antidiabetic drugs. There is increasing demand by patients in the rural areas of the world to use the natural products with antidiabetic activity. These set of people constitutes at least $80 \%$ of the world population. In recent times there has been renewed interest in the plant remedies even among the people in the urban areas. Plants hold definite promises in the management of Diabetes mellitus. In future, isolation \& identification of active constituents from these plants, preparation of standardized dose \& dosage regimen can play a significant role in improving the hypoglycaemic action.

\section{Acknowledgment}

Authors wish to acknowledge the immense contribution of members of staff of the Faculty of Pharmacy, University of Lagos, Lagos, Nigeria for the use of their library. We also thank all the teaching and non-teaching staff of the Faculty of Pharmacy, University of Ibadan, Ibadan, Nigeria.

\section{References}

[1]. J. Mayfield, Diagnosis and classification of diabetes mellitus- New Criteria. J. Ame[rican academy of family physician, 58 (8)1998,11-15.

[2]. K. I. Rother, Diabetes treatment: bridging the divide. New England Journal of Medicine356(15) 2007, 1499-1501.

[3]. J. Lindstrom, M. Peltonen,J. G. Eriksson, A. Louheranta, M. Fogelholm, M. Uusitupa, J. Tuomilehto, High - fibre diet predicts long - term weight loss and decreased type 2 diabetes risk; the Finnish diabetes prevention study. Diabetologia49,2006, 912 920.

[4]. R. E Lamb, Review of therapeutic groups for type 1 diabetes mellitus patients. J.Diab. And endocr, 3(2), $2006,11-12$.

[5]. H. F. W.Dubois and V. Bankauskaite, Type 2 diabetes programme in Europe. J. Euro Observe, 7(2),2005, 5-6.

[6]. R.Razavi, Y.Chan, F. N. Afifiyan,X.J. Liu, X. Wan, J.Yantha, H. Tsui, L.Tang, S. Tsai, P.Santamaria, J.P.Driver, D.Serreze, N. W. Salter, H. M.Dosch,:Cell. 15,127(6), 2006, 1123-35.

[7]. Eberhart, M. S., Ogden, C., Engelgau, M., Cadwell, B., Hedley, A. A, Saydah, S. H. (2004): Prevalence of Overweight and Obesity Among Adults with Diagnosed Diabetes-United States, 1988-1994 and 1999-2002. Morbidity Mortality Weekly Rep.53(45), 1066-1068.

[8]. M. I.Harris, K. M. Flegal, C. C.Cowie, M. S. Eberhardt, D. E. Goldstein, R. R. Little, Prevalence of diabetes, impaired fasting glucose, and impaired glucose tolerance in U.S. adults: The Third National Health and Nutrition Examination Survey. Diabetes Care, 21,1998,18-24.

[9]. D. M. Nathan, P. A.Cleary,J. Y. Backlund,Intensive diabetic treatment and cardiovascular disease in patients with type 1 diabetes. N. Engl. J. Med. 353, 2005, 2643.

[10]. T. Deckert,J. E. Poulsen and M. Larsen, Late diabetic manifestations in pancreatogenic diabetes mellitus. Act Diabetol Lat15, $1978,201-204$.

[11]. $\quad$ A.R Andersen, J. S. Christiansen,J. K. Andersen, S. Kreiner, T. Deckert, Diabetic nephropathy in Type 1 (insulin dependent) diabetes: an epidemiological study. Diabetologia, 25,1983, 496-501

[12]. D. J. Ballard,L. L. Humphrey, L. J. Melton, Epidemiology of persistent proteinuria in type 11 diabetes mellitus: population-based study in Rochester, Minnesota, Diabetes; 25, 1998, 496-412.

[13]. J. V. Selby, S. C. FitzSimmons, J. M. Newman, P. P. Katz,S. Sepe, J. Showstack, The natural history and epidemiology of diabetic nephropathy: implications for prevention and control. JAMA263, 1990, 1954-1960.

[14]. G. Viberti, H. Keen, The patterns of proteinuria in diabetes mellitus.Relevance to pathogenesis and prevention of diabetic nephropathy. Diabetes J. 33(7),1984,686-692.

[15]. G. C.Viberti, R. D. Hill, R. J. Jarrett, A. Argyropoulos, U. Mahmud, H. Keen,Microalbuminuria as a predictor of clinical nephropathy in insulin-dependent diabetes mellitus. Lancet. 26:1(8287), 1982, 1430-1432.

[16]. E. R. Mathiesen B. Oxenboll, K. Johansen, P. A. Svendsen, T. Deckert, Incipient nephropathy in type 1 (insulin-dependent) diabetes. Diabetologia26,1984, 406-410.

[17]. C. E. Mogensen, Microalbuminuria predicts clinical proteinuria and early mortality in maturity-onset diabetes. N. Engl. J. Med. $310,1984,356-360$. 
[18]. M. J. Kussman, H. H. Goldsten R. E. Gleason, The clinical course of diabetic nephropathy. JAMA, 236, 1976, $1861-1863$.

[19]. M. Nathan, Long-term complications of diabetes mellitus. N Engl J Med. 10, 328(23), 1993, 1676-1685.

[20]. R. W. Bilous, S. M. Mauer, D. E. R. Sutherland, M. W. Steffes, Mean glomerular volume and rate of development of diabetic nephropathy. Diabetes; 38, 1989, 1142-1147.

[21]. J. Pirart, Diabetes mellitus and it`s degenerative complications: A prospective study of 4,400 patients observed between 1947 and 1973. Diabetes Care, 1, 1978,168-87.

[22]. A. S. Krolewski, J. H. R. Warram, A. R. Christlieb, E. J. Busick, C. R.Kahn, Risk of proliferative diabetic retinopathy in juvenile-onset type 1 diabetes: a 40-year follow-up study. Diabetes Care; 9, 1986, 443-452.

[23]. G. Said, C. Gordon-Goeau, G. Slama, G. Tchobroutsky, Severe early- onset polyneuropathy in insulin-dependent diabetes mellitus: a clinical and pathological study. N. Engl. J. Med. 326, 1992, 1257-1263.

[24]. M. Ellenberg, Diabetic neuropathic cachexia. Diabetes23, 1974, 418-423.

[25]. W. B. Kanne and D. L. McGee, Diabetes and Cardiovascular Disease: the Framingham study. JAMA, 241, 1979, $2035-2038$.

[26]. [26] D. E. Singer, A. W. Moulton,D. M. Nathan, Diabetic myocardial infarction: interaction of diabetes with other pre infarction risk factors. Diabetes38, 1989, 350-357.

[27]. J. R. Margolis, W. S. Kannel, M. Feinleib, T. R. Dawber, P. M. McNamara, Clinical features of unrecognized myocardial infarction -- silent and symptomatic eighteen year follow-up: the Framingham study. Am J Cardiol.32, 1973, 1-7.

[28]. L. Rytter, S. Troelsen, H. Beck-Nielsen, Prevalence and mortality of acute myocardial infarction in patients with diabetes. Diabetes Care, 8, 1985, 230 - 234

[29]. R. J. Jarrett, P. McCartney, H.Keen, The Bedford Survey: ten year mortality rates in newly diagnosed diabetics and normoglycaemic controls and risk indices for coronary heart disease in borderline diabetics. Diabetologia; 22, 1982, 79-84

[30]. T. Gordon,W. P. Castelli,M. C. Hjjortland, High density lipoproteins as a protective factor against coronary heart disease: the Framingham study. Am JMed, 62, 1977, 707.

[31]. L. J. Wheat, Infection and diabetes mellitus. Diabetes Care, 3, 1980, 187-197

[32]. L. C. Perlmuter, M. K. Hakami and C. Hodgson-Harrington, Decreased cognitive function in aging non-insulin-dependent diabetic patients. Am. J. Med., 77, 1984, 1043-1048

[33]. WHO (1985): Study group report on diabetes mellitus. WHO technical report series 727, 1-113, WHO Geneva

[34]. F. J. Brinker, Herb Contraindictions and Drug Interactions: With Appendices Addressing Specific Conditions and Medicines. 2nd Edn., Eclectic Medical British Pharmacopoeia (1980): Ash value, Acid Insoluble Water Soluble, Extractive and Alcohol Extractive, Vol. II, Appendix XII, Majesty's Stationery Office, London, 1998, 1276 - 1277.Publications, Oregon, USA.

[35]. W. E. Basch, S. GabardiC. and Ulbricht, Musa sapientum, Am J Health-Syst Pharm. 60, 2003

[36]. C. Day, T. Cartwright, J. Provost, C. J. Bailey, Hypoglycaemic effect of Momordica charantia extracts. Planta Med., 56, 1990, 426-429.

[37]. H. Higashino,A.Suzuki, K. Tanaka Pootakham, Hypoglycaemic effects of Siamese MomordicaCharantia and Phyllantus urinaria extracts instreptozotocin-induced diabetic rats,Nippon Yakurigaku Zasshi, 100, 1992, 515-521.

[38]. S. Sarkar, M. Pranava, R. Marita, Demonstration of the hypoglycaemic action of Momordica Charantia in a validated model of diabetes. Pharmacol Res 33, 1996, 1-4.

[39]. N. C. Neogi, and K. P. Nayak, Biological investigation of Caesalpinia bonducella Flem, Indian Journal of Pharmacy20, 1958, 95-100.

[40]. M. A. Iyengar, G. S. Pendse, Anti-diarrhoeal activity of the nut of Caesalpinia bonducella Flem. Indian J. Pharmacol. 27, 1965, 307-308

[41]. M. L. Dhar, M. M. Dhar, B. N. Dhawan, B. N. Mehrotra and C. Ray, Screening of Indian plants for biological activity, Indian J. of Exp Biol.6, 1968,232

[42]. S. Gayaraja S. Shinde and S. L. Agarwal, Antiasthmatic properties of Caesalpinia bonducella leaves, Indian J. of Pharmacy10, 1978,86

[43]. K. Raghunathan, andK. M. Mitra in K. Raghunathan and R. Mitra, Editors, Pharmacognosy of Indigenous drugs. Part I, Central Council for Research in Ayurveda and Siddha, New Delhi, 1982, 484-510.

[44]. V. V. Rao, S. K. Dwivedi, and D. Swarup, Hypoglycemic effect of Caesalpinia bonducella in rabbits, FitoterapiaLXV, 1994, $245-247$.

[45]. T. K. Biswas,S. Bandyopadhyay, B. Mukherjee, B. Mukherjee and B. R. Sengupta, Oral hypoglycemic effect of Caesalpinia bonducella, Int. J. of Pharmacognosy35, 1997, 261-264.

[46]. S. Chakrabarti,T. K. Biswas, B. Rokeya, M. Mosihuzzaman, L. Ali, N. Nahar and B. Mukherjee, Advanced studies on hypoglycemic effect of Caesalpinia bonducella F. in, type 1 and 2 diabetes in Long-Evans rats, J. of Ethnopharmacology 84, 2003, 41-46.

[47]. S. R. Sharma, S. K. Dwivedi,D. Swarup, Hypoglycaemic, antihyperglycaemic and hypolipidemic activities of Caesalpinia bonducella seeds in rats. JEthnopharmacol58, 1997, 39-44.

[48]. R. Roman-Ramos, F. Alarcon-Aguilar, A. Lara-Lemus, J. L. Flores-Saenz, Hypoglycaemic effect of plants used in Mexico as antidiabetics. Arch Med Res; 23, 1992, 59-64

[49]. I. Lemus, R. Garcia, E. Delvillar, G. Knop, Hypoglycaemic activity of four plants used in Chilean popular medicine. Phytother Res.,13, 1999, 91-94.

[50]. J. A. Milner, S. S. McDonald, D. E. Anderson and P. Greenwald, Molecular targets fornutrients involved with cancer prevention. Nutr Cancer;41, 2001, 1-16.

[51]. J. A. Milner, S. S. McDonald, D. E. Anderson and P. Greenwald, Molecular targets fornutrients involved with cancer prevention. Nutr Cancer; 41, 2001, 1-16.

[52]. R. D. Sharma, T. C. Raghuran, and N. S. Raos, Effect of fenugreek seeds on blood glucose and serum lipids in type I diabetes. Eur. J. Clin. Nutr, 44, 1990, 301-306.

[53]. Z. Madar, R. Abel, S. Samish,J. Arad, Glucose-lowering effect of fenugreek in non-insulin dependent diabetics. Eur J Clin Nutr, 42, 1988, 51-4.

[54]. J. Shani, A. Goldschmied, B. Joseph, Z. Ahronson, F. G. Sulman, Hypoglycemic effect of Trigonella foenum-graecum and Lupinus termis (Leguminosae) seeds and their major alkaloids in alloxan-diabetic and normal rats. Achievements of International PharmacodynamicalTherapy 210, 1974, 27-37.

[55]. G. Ribes, Y. Sauvaire, C. Da Costa, J. C. Baccou, M. M Loubatieres-Mariani,Antidiabetic effects of subfractions from fenugreek seeds in diabetic dogs. Proceedings of the Society for Experimental Biology and Medicine 182, 1986, 159-166.

[56]. R. M. Amin, S. A. Abfdul-Salam, S. S. Mohammad, Effect of Fenugreek and Lupine seeds on the development of experimental diabetes in rats. Planta Medica54, 1988, 286-289. 
[57]. L. Ali, A. K. Azad-Khan, Z. Hassan, Z., Characterization of the hypoglycemic effects of Trigonella foecum graecum seed. Planta Med., 61, 1995, 101-110.

[58]. J. A. Abdel - Barry, M. H. Abdel - Hassan, Hypohlycaemic and antihypoglycaemic effects of Trigonella foenum - graecum leaf in normal and alloxan induced diabetic rats. J. Ethnopharmacol. 58, 1997, 149 - 155

[59]. M. Al-Habbori,A. Raman, Antidiabetic and hypocholesterolemic effects of fenugreek. Phytotherapy Research12, 1998, 233-242

[60]. M. P. J. Gomez, G.Bhaskar, Antidiabetic effects of fenugreek seed extract (Trigonella foenum-graecum) on Anabas testudineus with special reference to carbohydrate metabolism. Journal of Ecotoxicology \& Environmental Monitoring8, 1998, $103-106$.

[61]. A. M. M. Khatir, X. L. Ding, T. Fang, Hypoglycemic effect of fenugreek gum on normal and alloxan diabetic rats. Journal of Wuxi University of Light Industry 18, 1999, 16-20.

[62]. A. Gupta, R. Gupta B. Lal, Effect of Trigonella foenum - graecum seeds on glucaemic control and insulin resistance in type 2 diabetes mellitus, Journal Assoc PhysiciansIndia, 49, 2001, 1057 - 1061.

[63]. V. Vats, J. K. Grover, S. S. Rathi, Evaluation of anti-hyperglycemic and hypoglycemic effect of Trigonella foenum-graecum Linn, Ocimumsanctum Linn and Pterocarpus marsupium Linn in normal and alloxanized diabetic rats. Journal of Ethnopharmacology79, 2002, 95-100.

[64]. J. Raju,D. Gupta, A. R. Rao, P. K. Yadava and N. Z. Baquer,Trigonella foenum graecum (fenugreek) seed powder improves glucose homeostasis in alloxan diabetic rat tissues by reversing the altered glycolytic, gluconeogenic and lipogenic enzymes. Mol Cell Biochem; 224, 2001, 45-51.

[65]. T.Murakami, A. Kishi, H. Matsuda, M. Yoshikawa, Medicinal foodstuffs. XVII. Fenugreek seed (3): structures of new furostanol-type steroid saponins, trigoneosides Xa, Xb, XIb, XIIa, XIIb, and XIIIa, from the seeds of Egyptian Trigonella foenum graecum L.Chem Pharm Bull (Tokyo); 48, 2000,994-1000.

[66]. M, Yoshikawa,T. Murakami, M. Kadoya, Y. H. Li, N. Murakami, J. Yamahara, H. Matsuda, Medicinal foodstuffs. IX. The inhibitors of glucose absorption from the leaves of Gymnema sylvestre R. Br. (Asclepiadaceae): structures of gymnemosides a and b. Chemical \& Pharmaceutical Bulletin45, 1997, 1671-1676.

[67]. N. A. Al-Rowais, Herbal medicine in the treatment of diabetes mellitus; Saudi Med J., 23, 2002, 1327-1331.

[68]. R. D. Sharma, T. C. Raghuran, N. S. Raos, Effect of fenugreek seeds on blood glucose and serum lipids in type I diabetes. Eur. J. Clin. Nutr,44, 1990, 301-306.

[69]. P. Khosla, D. D. Gupta, R. K. Nagpal, Effect of Trigonella foenum graecum (Fenugreek) on blood glucose innormal and diabetic rats. Indian J Physiol Pharmacol.,39, 1995, 173-174.

[70]. P. R. Petit,Y. D. Sauvaire, D. M. Hillaire-Buys, Steroid saponins from fenugreek seeds: extraction, purification, and pharmacological investigation on feeding behavior and plasma cholesterol. Steroids. 60, 1995, 674-80

[71]. Y. Sauvaire, P. Petit, C. Broca, M. Manteghetti, Y. Baissac, J. Fernandez-Alvarez, R. Gross, M.. Roye, A. Leconte, R. Gomis, G. Ribes, 4-Hydroxyisoleucine: a novel amino acid potentiator of insulin secretion. Diabetes 47, 1998, 206-210.

[72]. P. Ravikumar, C. V. Anuradha, Effect of fenugreek seeds on blood lipid peroxidation and antioxidants in diabetic rats. Phytother Res;13, 1999, 197-201.

[73]. F. J. Larcon-Aguilar,R. Roman-Ramos, S. Perez-Gutierrez, Study of the antihyperglycaemic effect of plants used as antidiabetics. J Ethnopharmacol. 61,1998,101-110

[74]. R. C. Jain, D. B. Konar, Blood sugar lowering activity of garlic (Allium sativum Linn). Medikon 6, 1977, 15-18.

[75]. S. Patumraj, S. Tewit, V. Kasantikul, W. Udayachalerm,Effects of garlic extract on plasma insulin, lipid profiles and coronary vascular changes in STZ-rats, Messmer, K., Kuebler, W.M. (Eds.), World Congress for Microcirculation (Monduzzi Editore, Bologna 1996) 989-994.

[76]. H. H. Al-Zuhair, M. I. El-Sayed, M. A. Sadek, Hypoglycemic effect of the volatile oils of Nigella sativa and Allium sativum and their interactions with glipizide on alloxan diabetic rats. Bulletin of the Faculty of Pharmacy (Cairo University) 34, 1996, $101-104$.

[77]. G. R. Kumar, K. P. Reddy, Reduced non receptive responses in mice with alloxan induced hyperglycemia after garlic (Allium sativum Linn.) treatment. Indian Journal of Experimental Biology 37, 1999, 662-666.

[78]. R. Dong, Y. Q. Duan, X. Y. Wang, Y. Liu, G. L. Gao, Effect of garlic on peroxidation in rats with diabetes,Chinese Journal of Public Hygiene 16, 2000, 605-606.

[79]. C. Sheela, and K. T. Augusti, Antidiabetic effects of onion and garlic sulfoxide amino acids in rats. Planta Med.,61, 1995, 356357.

[80]. P. T. Mathew, K. T. Augusti, Effect of allicin (diallyl disulfide oxide) on alloxan diabetes. I. Hypoglycemic action and enhancement of serum insulin effect and glycogen synthesis. Indian Journal of BiochemicalBiophysiology 10, 1973, $209-212$.

[81]. N. Han, Y. Wang, Study on the mechanism of allicin to experimental diabetes mellitus. Chinese Pharmacological Bulletin 13, 1991, 30-31

[82]. C. G. Sheela, K. T. Augusti, Antidiabetic effects of S-allyl cysteine sulfoxide isolated from garlic Allium sativum Linn. Indian, Journal of Experimental Biology 30, 1992523-526.

[83]. K. T. Augusti, C. G Sheela, Antiperoxide effect of Sallyl - cystein sulfoxide, an insulin secretagogue in diabetic rats. Experientia; $52,1996,115-120$

[84]. H. Al-Zuhair, B.-Sayed, H. Al - Shoora Pharmacological studies on cardamom oil in animals, Pharmacological research, 34, $1996,79-82$.

[85]. K. Kumari, B. C. Mathew, K. T. Augusti, Antidiabetic and hypolipidemic effects of S-methyl cysteine sulfoxide isolated from Allium cepa Linn. Indian J.Biochem Biophys., 32, 1995, 49-54.

[86]. P. S. Babu and K. Srinivasan, Influence of dietary capsaicin and onion on the metabolic abnormalities associated with streptozotocin induced diabetes mellitus. Mol Cell Biochem, 175, 1997, 49-57.

[87]. M. A. Ajabnoor, Effects of aloes on blood glucose levels in normal and alloxan diabetic mice, J Ethnopharmacol, 28, 1990, 215 220 ,

[88]. R. R. Chattopadhyay, Possible mechanism of antihyperglycaemic effect of Azadirachta indica leaf extract, part IV. Gen Pharmacol, 27, 1996, 431-434.

[89]. R. R. Chattopadhyay, Possible mechanism of antihyperglycaemic effect of Azadirachta indica leaf extract, part V. J. Ethnopharmacol, 67, 1999, 373-376.

[90]. A. Helmstoadter,Syzygium cumini (L.) skeels (Mrytaceae) against diabetes-125 years of research.Pharmazie, 63, 2008, 91-101.

[91]. S. Achrekar, G. S. Kaklij, M. S. Pote, S. M. Kelkar, Hypoglycaemic activity of Eugenia jambolana and Ficus bengalensis: Mechanism of action. J. In vivo, 5, 1991, 143-147.

[92]. P. S. Prince, V. P. Menon, L. Pari, Hypoglycaemic activity of Syzigium cumini seeds: effect on lipid peroxidation in alloxan diabetic rats. J. Ethnopharmacol; 61, 1998, 1-7 
[93]. F. J. Alarcon-Aguilar, R. Roman-Ramos, S. Perez-Gutierrez, Study of the antihyperglycaemic effect of plants used as antidiabetics. J Ethnopharmacol. 61, 1998, 101-110.

[94]. L. Pari and J. Umamaheswari, Antihyperglycaemic activity of Musa sapientum flowers: effect on lipid peroxidation in alloxan diabetic rats. Phytother Res; 14, 2000, 136-138.

[95]. S. O. Majekodunmi, and O. A. Odeku, Formulationstudies on Mucuna pruriens seed extract into tablet dosage form for the treatment of diabetes mellitus, seminar presentation, Department of Pharmaceutics and Industrial Pharmacy, Faculty of Pharmacy, University of Ibadan, Ibadan, Nigeria, 2011.

[96]. G. Dabis, D. Michon,J. Gazenav, A. Ruffie, Hypoglycemic effect of Sueda fruticosa in streptozotocin- induced diabetic rats. La vie medicale8, 1984, 277

[97]. G. Don,Medicinal plants of the world(Ross I.A. Ed, Humana Press, N.J: Totowa, 1999) 109-118

[98]. S. N. Singh, P. Vats, S. Suri, R. Shyam, M. M. Kumria, S.Ranganathan, K. Sridharan. Effect of an antidiabetic extract of Catharanthus roseus on enzymic activities in streptozotocin induced diabetic rats. Journal of Ethnopharmacology76, 2001, 269277.

[99]. R. K. Ghosh, I. Gupta,Effect of Vinca rosea and ficus racemososus on hyperglycemia in rats, Indian J. Anim. Health, 19,1980, 145

[100]. R. R. Chattopadhyay, S. K Sarkar, S. Ganguly, R. N. Banerjee, T. K. Basu, Hypoglycemic and anti-hyperglycemic effect of Vinca rosea Linn, .Ind.JPhysi ofPharmacol, 35, 1991, 145-15

[101]. R. R./ Chattopadhyay, S. K. Sarkar, S. Ganguli, Indian J. Physiol. Pharmacol. 36, 1980, 291

[102]. W. L. Li, H. C. Zheng, J. Bukuru, N. De Kimpe, Natural medicines used in the traditional Chinese medical system for therapy of diabetes mellitus, J. of Ethnopharmacology 92, 2004,1-12

[103]. S. Nammi, M. K. Boini, S. D.Lodagala, R. B. Behara, The juice of fresh leaves of Catharanthus roseus Linn, reduces blood glucose in normal and alloxan diabetic rabbits. BMC Complement Altern Med, 2, 2003, 3-4.

[104]. H. M. Mukhtar, S. H. Ansari, Z. A. Bhat, T. Naved, P. Singh, Antidiabctic activity of an ethanol extract obtained from the stem bark of Psidiumguajava (Myrtaceae). Pharmazie, 61, 2006, 725-727

[105]. J. T. Cheng, R. S.Yang, Hypoglycemic effect of guava juice in mice and human subjects. American Journal of Chinese Medicine $11,1983,74-76$.

[106]. Y. Maruyama, H. Matsuda, R. Matsuda, M. Kubo, T. Hatano, T. Okuda, Study on Psidium guajava L. (I). Antidiabetic effect and effective components of the leaf of Psidium guajava L. (Part 1). Shoyakugaku Zasshi 39, 1985, 261-269.

[107]. P. Basnet, S. Kadota, R. R. Pandey, T. Takahashi, Y. Kojima, M. Shimizu, Y. Takata, M. Kobayashi, T. Namba, Screening of traditional medicines for their hypoglycemic activity in streptozotocin (STZ)-induced diabetic rats and a detailed study on Psidium guajava. WakanIyakugaku Zasshi 12,1995, 109-117.

[108]. Y. Deguchi, K. Osada, K. Uchida, H. Kimura, M. Yoshikawa, T. Kudo, H. Yasui, M. Watanuki, Effects of extract of guava leaves on the development of diabetes in the mouse and on the postprandial blood glucose of human subjects, Nippon Nogei KagakuKaishi 72, 1998, 923-931.

[109]. P. K. Rai, S. Mehta, G. Watal, Hypolipidaemic \& hepatoprotective effects of Psidium guajava raw fruit peel inexperimental diabetes. Indian J Med Res, 131, 2010, 820-824.

[110]. Saif - Ur-Rehman, A. J. Saghir, H. Sajid , A. Ishtiaq and N. Muhammad, Study on antidiabetic effect of Aloe vera extract on alloxan induced diabetic rats,Libyan Agriculture Research Center Journal International2 (1), 2011, 29 - 32.

[111]. A. Gupta, R. Gupta, B. Lal, Effect of Trigonella foenum-graecum (fenugreek) seeds on glycaemic control and insulin resistance in type 2 diabetes mellitus: a double blind placebo controlled study. Journal of the Association of Physicians of India 49, 2011, 1057-1061. 